\title{
Formation of hexagonal and cubic fluorescent periodic mesoporous organosilicas in the channels of anodic alumina membranes
}

\begin{abstract}
Yan Li, ${ }^{a}$ Andreas Keilbach, ${ }^{\mathrm{b}}$ Norihiro Mizoshita, ${ }^{\text {cd }}$ Shinji Inagaki ${ }^{\mathrm{cd}}$ and Thomas Bein ${ }^{\star a}$
The synthesis of periodic mesoporous organosilicas (PMOs) in the confinement of porous anodic alumina membranes (AAMs) was successfully achieved through a modified evaporation-induced self-assembly (EISA) process. 1,3,5-Tris(4-triethoxysilylstyryl)benzene, (a three-armed oligo(phenylenevinylene) organosilane compound, abbr. 3a-OPV), the precursor of the first reported charge-conducting PMO, was used as an organosilica source. Triblock-copolymers Pluronic F127 $\left(\mathrm{EO}_{106} \mathrm{PO}_{70} \mathrm{EO}_{106}\right)$ or F108 $\left(\mathrm{EO}_{132} \mathrm{PO}_{50} \mathrm{EO}_{132}\right)$ were used as structure directing agents. The block-copolymer $\mathrm{F} 127$ led to a 2D-hexagonal circular mesostructure within the AAM channels and the block copolymer Pluronic F108 resulted in a mesophase with a body-centered cubic $(I m \overline{3} m)$ structure. Compared to the previously reported 3a-OPV-PMO film, the resulting hierarchical PMO/AAM systems have improved features, that is, the synthesized PMOs have a pore size of around $10 \mathrm{~nm}$ and the compounds are found to be stable against thermal treatment at temperatures of up to $200{ }^{\circ} \mathrm{C}$ and they are also stable in the electron beam of the electron microscope. Additionally, both of the resulting hierarchical mesoporous composites show fluorescence in the visible region due to the strongly interacting phenylenevinylene chromophores in the PMO frameworks.
\end{abstract}

Received 2nd January 2013

Accepted 13th August 2013

DOI: $10.1039 /$ c3tc00008g

www.rsc.org/MaterialsC systems. $^{6-9}$ The resulting functional porous materials can interact in different ways with guest molecules that reside in the pores, leading to potential applications of PMOs as catalysts, ${ }^{10,11}$ adsorbents, ${ }^{12,13}$ and optical ${ }^{14-17}$ systems. In recent years, great efforts have been made towards developing novel PMOs with photoactive or electroactive functions within their frameworks. ${ }^{18}$ Recently, a novel PMO material was reported by some of us with oligo(phenylenevinylene) molecules being incorporated into the pore walls and it was found to be charge-conducting (its charge carrier mobility was on the order of $10^{-5} \mathrm{~cm}^{2}$ $\left.\mathrm{V}^{-1} \mathrm{~s}^{-1}\right) \cdot{ }^{19}$ This PMO was synthesized as a film material on flat substrates. The synthesized film had mesopores with a fairly small diameter of $2.4 \mathrm{~nm}$ and possessed a hexagonal packing of the mesochannels judged by indexing the diffraction peaks in the X-ray diffraction pattern. However, direct imaging of such a PMO film by electron microscopy was difficult due to the collapse of the mesostructure under electron-beam irradiation. Therefore, improving the stability of this PMO material, tuning the mesopore size and controlling the mesochannel orientation remain as challenges to further develop its potential.

Recently, great efforts have been made to realize control over the domain size and orientation of mesoporous systems, including application of external electric ${ }^{20,21}$ or magnetic fields, ${ }^{22,23}$ or use of chemically ${ }^{24,25}$ or lithographically ${ }^{26}$ treated substrates. Moreover, an alternative strategy uses confinement in anisotropic hosts such as porous anodic alumina membranes (AAMs). ${ }^{27}$ The resulting mesoporous composites were reported to be able to offer \footnotetext{
(LMU), Butenandtstrasse 5-13 (E), Munich 81377, Germany. E-mail: tbein@lmu.de; ${ }^{b}$ Anton Paar GmbH, Anton-Paar-Str. 20, A-8054 Graz, Austria

'Toyota Central R\&D Laboratories Inc., Nagakute, Aichi 480-1192, Japan. E-mail: inagaki@mosk.tytlabs.co.jp; Fax: +81-561-63-6507

${ }^{d}$ Core Research for Evolutional Science and Technology (CREST), Japan Science and Technology Agency (JST), Kawasaki, Saitama 332-0012, Japan
} 
high mechanical and thermal stability due to the support of the alumina host. Furthermore, the confinement effects can lead to enhanced control over the resulting mesophase morphologies, with the possibility to realize large single-phase domains and high aspect ratios of mesoporous systems. ${ }^{28-34}$ Given the favorable interaction of silica species with AAM channel walls found in inorganic silica/AAM systems, we reasoned that combining PMO systems with porous AAM hosts might lead to a different phase behavior and phase stability, thus improving the quality of PMO materials and meanwhile opening the way to design novel hierarchical nanosystems. Based on our previous work on PMO/AAM composite systems, ${ }^{35,36}$ the present study focuses on the synthesis of the reported charge-conducting PMO within the confinement of AAM channels to achieve a new hierarchical PMO/AAM nanosystem that might move us closer to the application of PMO systems in optoelectronic devices.

In this study, 1,3,5-tris(4-triethoxysilylstyryl)benzene (a threearmed oligo(phenylenevinylene) organosilane compound, denoted as 3a-OPV) was used as an organosilica source to form PMO materials with Pluronic F127 or F108 as structure directing agents. Through a modified evaporation-induced self-assembly (EISA) process, ${ }^{37}$ highly ordered and stable 3a-OPV-PMO materials were successfully synthesized within AAM host systems. The resulting hierarchical 3a-OPV-PMO/AAM systems were found to be stable against thermal treatment at temperatures of up to $200{ }^{\circ} \mathrm{C}$ and also stable in the electron beam of an electron microscope. The pore diameters of the new PMO materials are around $10 \mathrm{~nm}$ due to the large sizes of the structure directing agents. With such large pore sizes, the resulting PMO materials offer compatibility with many other guest molecules, i.e., the mesochannels of PMOs can accommodate large molecules such as photo-reactive precursors or charge-transporting molecules, so that these PMO materials could offer potential for applications in photocatalytic and photovoltaic fields. Furthermore, all the 3a-OPV-PMO/AAM hierarchical materials showed fluorescence in the visible region due to the phenylenevinylene chromophores in the condensed organosilica frameworks.

\section{Experimental section}

\section{Preparation of 1,3,5-tris(styryl)benzene-bridged PMO in AAM channels}

The synthesis of PMO confined in AAM channels was achieved by the evaporation-induced self-assembly (EISA) approach. Whatman Anodiscs (47 mm diameter, $60 \mu \mathrm{m}$ thickness, 150$250 \mathrm{~nm}$ pore diameter) were used as porous alumina substrates. 1,3,5-Tris(4-triethoxysilylstyryl)benzene (3a-OPV) (Scheme 1) served as an organosilica precursor (provided by Toyota Central R\&D Laboratories Inc., Japan).

The preparation method for 1,3,5 tris(4-triethoxysilyl-styryl) benzene was reported in the ESI of the previous paper (ref. 18). Triblock co-polymer F127 (poly(ethylene oxide)-poly(propylene oxide)-poly(ethylene oxide), $\mathrm{EO}_{106} \mathrm{PO}_{70} \mathrm{EO}_{106}$, Sigma-Aldrich) and F108 $\left(\mathrm{EO}_{132} \mathrm{PO}_{50} \mathrm{EO}_{132}\right.$, Sigma-Aldrich) were used as structure directing agents (SDA). All chemicals were used without further purification. In the following, the 3a-OPV-PMO materials are named with the used SDA followed by the description

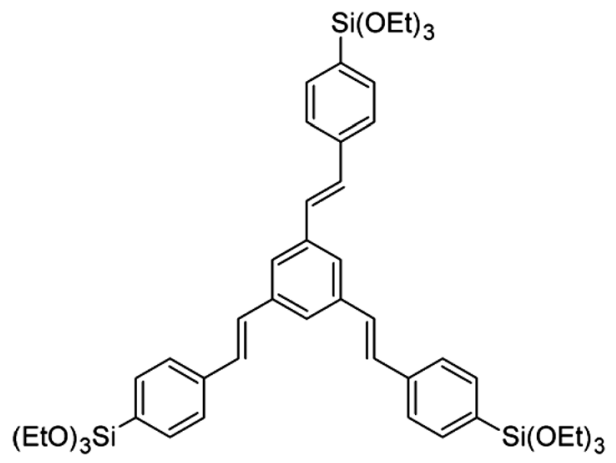

Scheme 1 Chemical structure of 1,3,5-tris(4-triethoxysilylstyryl) benzene, a three-armed oligo(phenylenevinylene) precursor (denoted as $3 a-O P V)$.

of the formed mesostructure, i.e., the samples synthesized by F127 and F108 are denoted as F127-circular and F108-cubic, respectively.

For the preparation of the sample F127-circular, 3a-OPV $(0.06 \mathrm{~g}, 0.067 \mathrm{mmol})$ and $\mathrm{F} 127(0.06 \mathrm{~g}, 0.005 \mathrm{mmol})$ were first dissolved in $2.316 \mathrm{~g}$ absolute $\mathrm{EtOH}$. Then, distilled $\mathrm{H}_{2} \mathrm{O}(0.030 \mathrm{~g}$, $1.7 \mathrm{mmol}$ ) was added and the solution was stirred for $10 \mathrm{~min}$. Next, $1 \mathrm{M} \mathrm{HCl}\left(4.2 \mu \mathrm{L}, 4.2 \times 10^{-3} \mathrm{mmol}\right)$ was added and the resulting solution was stirred for $2 \mathrm{~h}$. Finally, the AAM was placed on a Teflon plate and soaked with the above prepared precursor solution by drop-casting $0.75 \mathrm{~mL}$ of the solution over the whole membrane surface ( $47 \mathrm{~mm}$ diameter, with an area of $17 \mathrm{~cm}^{2}$ ). During the EISA-process, the ambient conditions were maintained at $45-55 \%$ relative humidity and $25{ }^{\circ} \mathrm{C}$.

For the preparation of the sample F108-cubic, the synthesis procedures followed the same protocol as above with the exception that $0.075 \mathrm{~g}$ F108 $(0.005 \mathrm{mmol})$ was added to the precursor solution instead of F127.

In order to remove the structure directing agents to get accessible mesopores, the PMO/AAM composites were calcined up to $200{ }^{\circ} \mathrm{C}$ with a heating ramp of $0.5{ }^{\circ} \mathrm{C} \mathrm{min}^{-1}$. Before reaching $200{ }^{\circ} \mathrm{C}$, the samples were kept at $120{ }^{\circ} \mathrm{C}$ for $5 \mathrm{~h}$ and finally kept for $10 \mathrm{~h}$ at $200{ }^{\circ} \mathrm{C}$.

\section{Characterization}

The samples were characterized by $2 \mathrm{D}$ small-angle X-ray scattering (2D-SAXS) using the SAXSess system by Anton Paar with a CCD detector (PI-SCX:4300, Roper Scientific). The wavelength of the incident beam is $0.154 \mathrm{~nm}\left(\mathrm{Cu} \mathrm{K}_{\alpha}\right)$, and the sample-detector distance was set to $308 \mathrm{~mm}$. Samples were measured with a tilt angle of $10^{\circ}$ with respect to the primary beam. Transmission electron microscopy (TEM) was performed using a JEOL 2011 with an acceleration voltage of $200 \mathrm{kV}$. Nitrogen sorption measurements were carried out at $-196{ }^{\circ} \mathrm{C}$ using an Autosorb- 1 by Quantachrome instruments. Prior to the measurement, the PMO/AAM composites were broken into small pieces (without dissolving the AAM host matrix) to fit the measurement cell. All samples were degassed at $150{ }^{\circ} \mathrm{C}$ for $12 \mathrm{~h}$ in a vacuum. The Brunauer-Emmett-Teller (BET) surface area was calculated using experimental points at a relative pressure range of 
$p / p_{0}=0.05-0.20$. The total pore volume was calculated by the $\mathrm{N}_{2}$ amount adsorbed at the point of $p / p_{0}=0.95$. NLDFT pore size distributions were calculated using an $\mathrm{SiO}_{2}$ kernel assuming a cylindrical pore geometry for the F127-circular sample and a cylindrical/sphere pore geometry for the F108-cubic sample. Solid-state ${ }^{13} \mathrm{C}$ and ${ }^{29} \mathrm{Si}$ NMR experiments were carried out with the broken and ground PMO/AAM composites (without dissolution of the AAM matrix) and performed on a Bruker Avance-III 500 spectrometer (11.7 Tesla) operating at frequencies of 125.8 $\mathrm{MHz}$ for ${ }^{13} \mathrm{C}$ and 99.4 MHz for ${ }^{29} \mathrm{Si} .{ }^{13} \mathrm{C}\left({ }^{1} \mathrm{H}\right) \mathrm{CP}-\mathrm{MAS}$ spectra were acquired using a $90^{\circ}$ pulse length of $2.5 \mu \mathrm{s}(3.7 \mathrm{~dB})$ with a crosspolarization contact time of $5 \mathrm{~ms}$ and a recycle delay of $2 \mathrm{~s}$. ${ }^{29} \mathrm{Si}\left({ }^{1} \mathrm{H}\right) \mathrm{CP}-\mathrm{MAS}$ experiments were conducted using a $90^{\circ}$ pulse length of $2.5 \mu \mathrm{s}(2.7 \mathrm{~dB})$ with a cross-polarization contact time of $5 \mathrm{~ms}$ and a recycle delay of $4 \mathrm{~s}$. The fluorescence spectra were measured with a fluorescence spectroscopy system (PTI 814 from Photon Technology international) with a xenon arc lamp.

\section{Results and discussion}

\section{F127-circular 3a-OPV-PMO}

Using Pluronic F127 as a structure directing agent, a circular hexagonal phase was observed within the AAM channels. In order to obtain an open pore system, the composite membranes were mildly calcined up to $200^{\circ} \mathrm{C}$. The highly ordered hexagonal circular structure was identified as the major phase by $2 \mathrm{D}$ small angle X-ray scattering (2D-SAXS) measurements. The 2D-SAXS pattern of the calcined sample (Fig. 1A) shows both in-plane (01) and out-of-plane (10) peaks that are characteristics of a circular hexagonal structure confined in AAM channels. ${ }^{35,38,39}$

The $d$-values calculated from the diffraction pattern are 14.5 $\mathrm{nm}$ and $15.6 \mathrm{~nm}$, corresponding to $d_{01}$ and $d_{10}$ respectively. The TEM image (Fig. 1B) of the calcined composite displays an electron-beam stable PMO with a highly ordered hexagonal circular structure as the predominant phase that is formed in the AAM channels. The measured $d$-value is $14 \mathrm{~nm}$, which is slightly smaller than the values resulting from the X-ray diffraction. This small difference can be attributed to the shrinkage of the porous system during the ion milling procedure, which is a crucial step in the TEM specimen preparation, as well as the effect of exposure to the electron beam under high vacuum in the TEM. We note that the orientation of the hexagonal mesostructures could be influenced by the size and

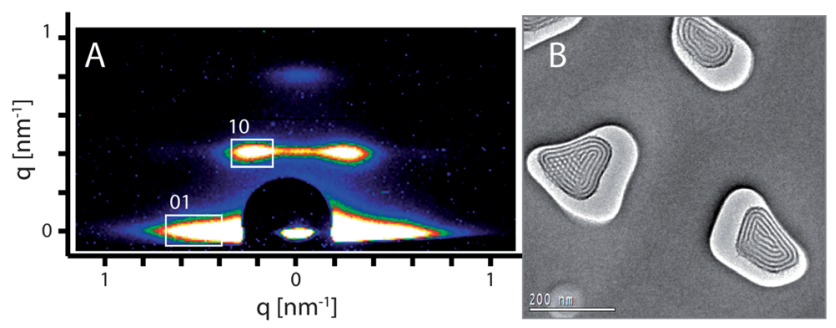

Fig. 1 (A) 2D-SAXS pattern and (B) plan-view TEM micrograph of the calcined PMO/AAM composite showing the highly ordered hexagonal circular structure of the 3a-OPV-PMO formed with F127 as a structure directing agent. shape of AAM channels. ${ }^{39}$ In a small number of the AAM channels, a hexagonal columnar structure was observed as a side phase (e.g. the channel on the left side in Fig. 1B).

The nitrogen sorption isotherm (Fig. 2A) of the calcined F127-circular PMO shows the typical type IV isotherm shape commonly observed with mesoporous materials. The Brunauer-Emmett-Teller (BET) surface area calculated from the isotherm is $57.3 \mathrm{~m}^{2} \mathrm{~g}^{-1}$ and the pore volume is $0.073 \mathrm{~cm}^{3}$ $\mathrm{g}^{-1}$ (the mass for the calculation includes the AAM host). The isotherm has a large hysteresis loop suggesting the existence of ink-bottle shaped pores in the PMO material. This can be confirmed by comparing the DFT pore-size distributions from the adsorption branch (av. pore diameter $\sim 9.4 \mathrm{~nm}$ ) and the desorption branch (av. pore diameter $\sim 5.3 \mathrm{~nm}$ ), both of which show sharp pore size distributions (Fig. 2B).

In the ${ }^{13} \mathrm{C}$-MAS NMR spectrum (Fig. 3A), the peaks at around $130 \mathrm{ppm}$ and their spinning side bands (indicated by asterisk) correspond to the 1,3,5-tris(styryl)benzene group, showing the preservation of the organic units in the mildly calcined F127circular PMO material. In addition, weak signals (at 17.6 and $75.3 \mathrm{ppm}$ ) can be attributed to small amounts of residual F127 molecules, indicating the incomplete removal of the structure directing agent. This incomplete removal of F127 possibly caused partial blocking of the large mesopores and thus led to the ink-bottle shaped pores, which is in agreement with the above nitrogen sorption result. The ${ }^{29} \mathrm{Si}$ NMR spectrum (Fig. 3B) shows resonances attributed to $\mathrm{T}^{2}$-silicon species $(\mathrm{RSi}(\mathrm{O}-$ $\mathrm{Si}_{2}(\mathrm{OH})$ ) at $-71.3 \mathrm{ppm}$ and $\mathrm{T}^{3}$ species $\left(\mathrm{RSi}(\mathrm{OSi})_{3}\right)$ at $-80.2 \mathrm{ppm}$,
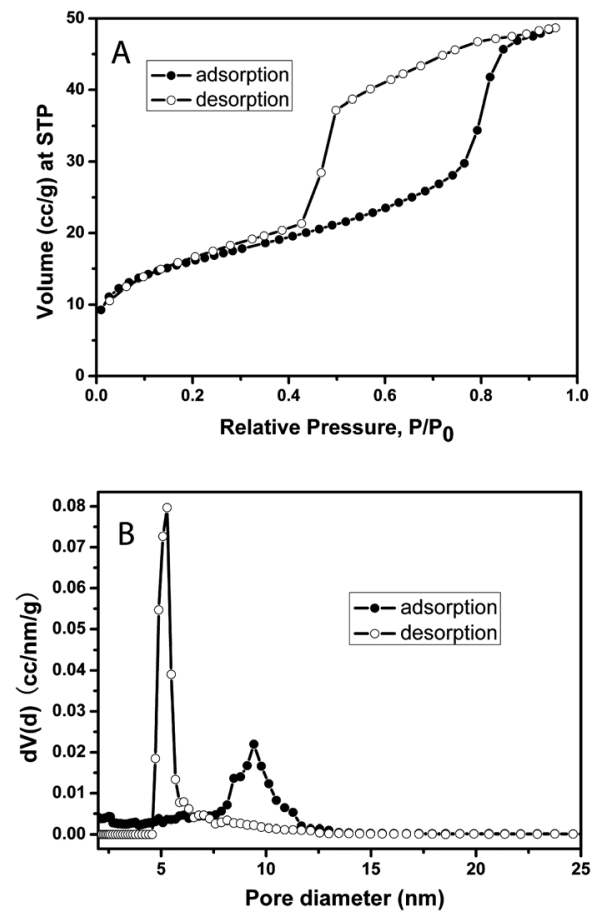

Fig. 2 (A) Nitrogen adsorption $(\mathbf{)})$ and desorption $(\mathrm{O})$ isotherms of the calcined F127-circular sample and (B) pore size distributions calculated by a NLDFT method from both the adsorption branch ( and desorption branch $\left(\mathrm{O}\right.$ ) by using an $\mathrm{SiO}_{2}$ kernel assuming a cylindrical pore geometry. 


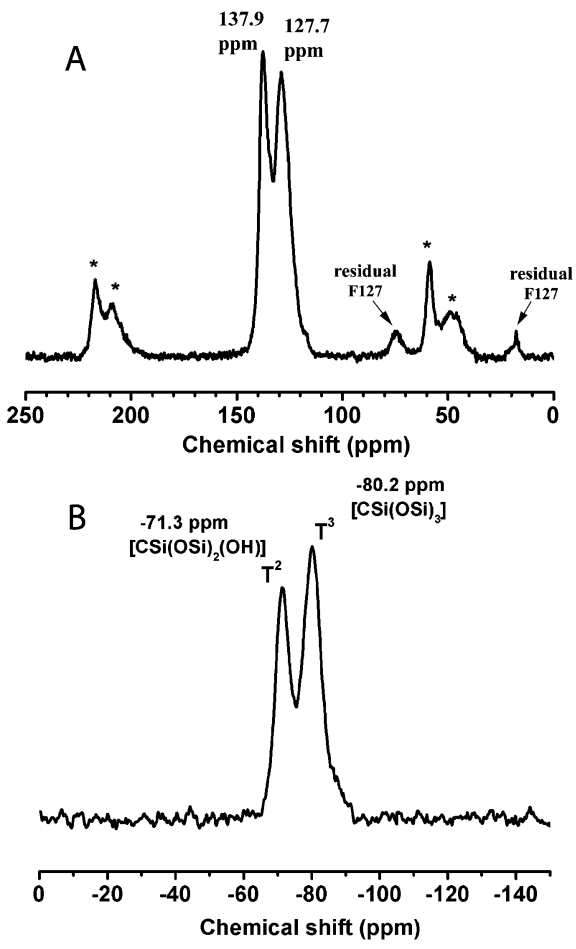

Fig. 3 (A) ${ }^{13} \mathrm{C}$-MAS NMR and (B) ${ }^{29} \mathrm{Si}$ NMR spectra of the calcined F127-circular sample, showing the almost complete removal of the surfactant F127, the highly condensed $\mathrm{Si}-\mathrm{O}-\mathrm{Si}$ network and the preserved $\mathrm{Si}-\mathrm{C}$ bonds in the obtained stable PMO material. (Signals marked with asterisk denote the spinning side bands of the tris(styryl) benzene groups.)

suggesting a high degree of polycondensation of the organosilane precursors in the formed PMO pore walls. It is also noteworthy that no resonance appears in the Q-site region (around $100 \mathrm{ppm}$ ), indicating that the $\mathrm{Si}-\mathrm{C}$ bonds were quite stable in the framework of the 3a-OPV-PMO material under all the conditions of preparation and thermal treatment.

\section{F108-cubic 3a-OPV-PMO}

A second mesophase was created by using the triblock co-polymer F108 as a structure directing agent. Compared to Pluronic F127 $\left(\mathrm{EO}_{106} \mathrm{PO}_{70} \mathrm{EO}_{106}\right)$, template $\mathrm{F} 108\left(\mathrm{EO}_{132} \mathrm{PO}_{50} \mathrm{EO}_{132}\right)$ is a relatively hydrophilic surfactant with longer hydrophilic EO chains and shorter hydrophobic PO parts, which leads to micelles with higher curvature in the solution. ${ }^{40}$ Thus, we reasoned that after replacing F127 with F108 into a solution that originally could result in a $2 \mathrm{D}$ hexagonal (circular) structure, a new structure would be formed. 2D-SAXS measurements were carried out to identify the mesostructure of the PMO templated by F108. The SAXS pattern recorded with the calcined sample shows the typical peaks assigned to a body centered cubic $\operatorname{Im} \overline{3} m$ phase (Fig. 4A), similar to recent observations with other cubic phase in AAM hosts, ${ }^{36,39}$ indicating that a new 3a-OPV-PMO with a cubic structure was formed. The formation of the cubic mesostructure was also confirmed by the TEM micrographs. The average $d$-value resulting from the SAXS pattern is $17.4 \mathrm{~nm}$, which is in good agreement with the value $\left(d_{110}=17 \mathrm{~nm}\right)$
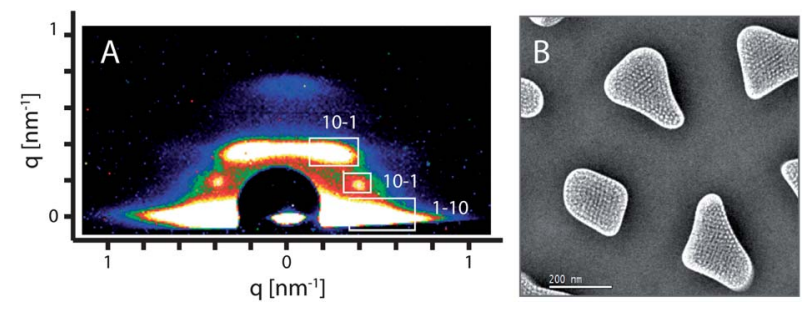

Fig. 4 (A) 2D-SAXS pattern and (B) plan-view TEM micrograph of the calcined F108-cubic PMO, representing a highly ordered body centered cubic structure with only minor shrinkage after thermal treatment.

obtained from the TEM image. A plan-view TEM micrograph of the calcined F108-cubic sample is displayed in Fig. 4B. It is remarkable that the F108-cubic PMO material within the AAM channels shows minor shrinkage; we attribute this to the threedimensional connection existing in the cubic structure combined with the spatial confinement in the AAM host.

The porosity properties were determined by nitrogen sorption. Fig. 5 depicts the isotherms of the calcined F108-cubic sample, showing the type IV shape with a very wide adsorptiondesorption hysteresis that is attributed to large mesopores connected by smaller open windows in the cubic system. The BET surface area of the calcined F108-cubic composite is $37 \mathrm{~m}^{2}$ $\mathrm{g}^{-1}$ and the pore volume is $0.071 \mathrm{~cm}^{3} \mathrm{~g}^{-1}$ (the mass includes the AAM membrane). The pore-size distribution (calculated from the adsorption branch) shows a pore diameter of $14.0 \mathrm{~nm}$.

The ${ }^{13} \mathrm{C}$ and ${ }^{29} \mathrm{Si}$ NMR data (Fig. 6) of the calcined F108-cubic sample are consistent with those obtained from the F127circular system. All the characterization results show that a body centered cubic 3a-OPV-PMO is successfully formed with electron beam stability as well as thermal stability up to $200{ }^{\circ} \mathrm{C}$.

\section{Fluorescence emission of 3a-OPV-PMO/AAM composites}

Fluorescence emission spectra were recorded from both 3a-OPV-PMO/AAM composites and from a diluted isopropanol solution of 3a-OPV precursor (Fig. 7).

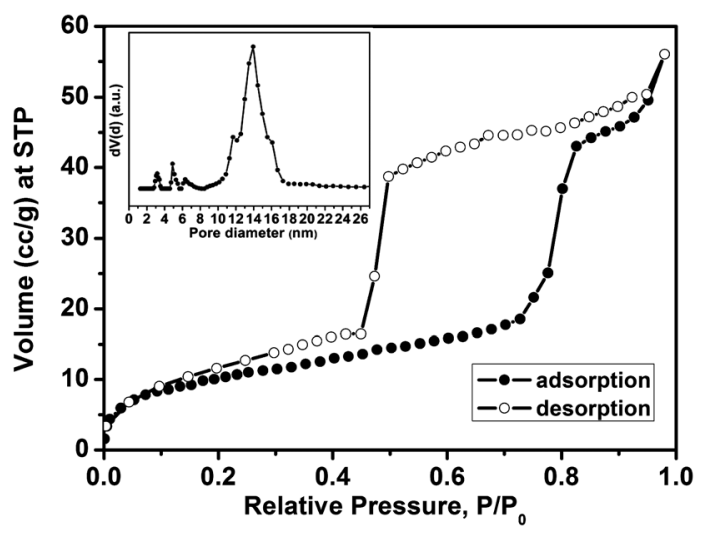

Fig. 5 Nitrogen sorption isotherms of the calcined F108-cubic sample with an inset showing the corresponding pore size distribution calculated with a NLDFT method using the adsorption branch with a $\mathrm{SiO}_{2}$ kernel assuming a cylindrical/spherical pore geometry. 


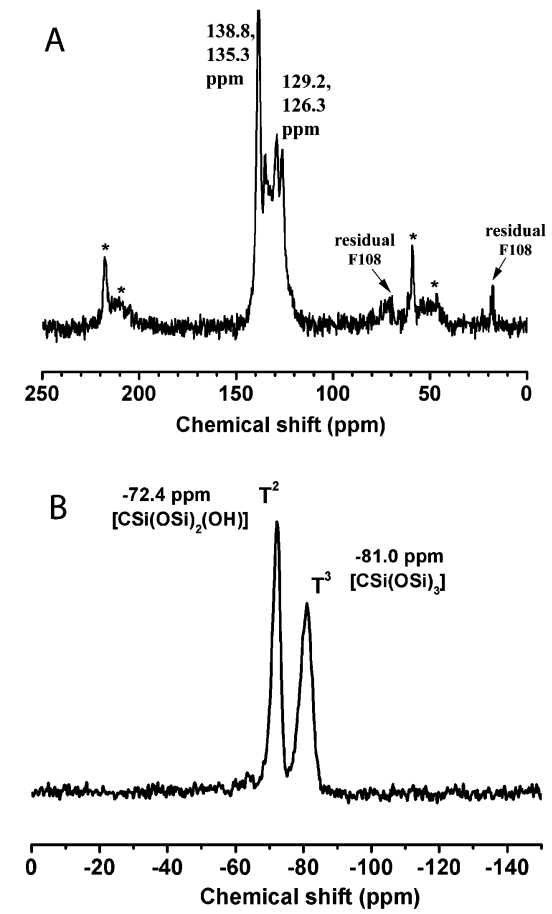

Fig. 6 (A) ${ }^{13} \mathrm{C}-$ MAS NMR and (B) ${ }^{29} \mathrm{Si}$ NMR spectra of the calcined F108cubic sample, showing the almost complete removal of the template Pluronic F108 and the high degree of condensation of the Si-O-Si network. (Signals marked with asterisk denote the spinning side bands.)

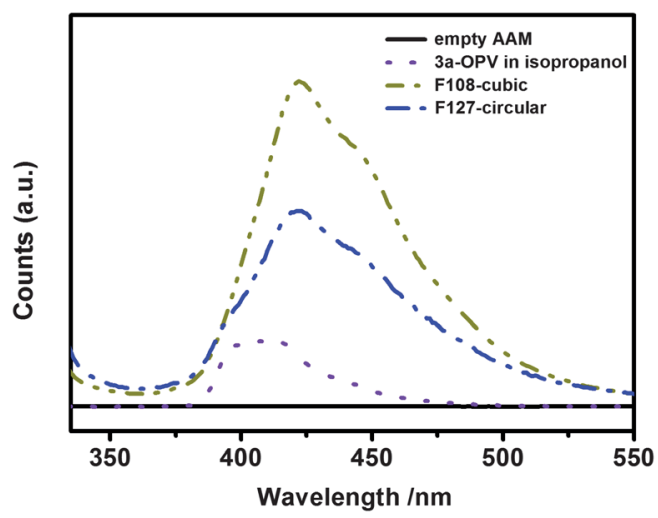

Fig. 7 Fluorescence spectra (excited at $320 \mathrm{~nm}$ ) of the circular and cubic-structured 3a-OPV-PMO confined in AAM channels and a diluted 3a-OPV precursor solution in isopropanol $\left(10^{-5} \mathrm{M}\right)$ (the intensities are not to scale).

The resulting hierarchically structured 3a-OPV-PMO/AAM composites were observed to be fluorescent in the visible light region. The fluorescence emission bands of both circular and cubic PMO/AAM composites peak at a wavelength of $422 \mathrm{~nm}$, which indicates a slight shift to longer wavelength with respect to the fluorescence emission of the diluted precursor solution $\left(10^{-5} \mathrm{M}\right.$ in isopropanol) peaking at $410 \mathrm{~nm}$. The broadening and energy shift of the emission bands of the obtained PMOs indicate that the phenylenevinylene chromophores are still active and that they experience intermolecular electronic interactions in the confined organosilica networks.

\section{Conclusions}

In summary, phenylenevinylene-bridged periodic mesoporous organosilica materials with tunable mesostructures were successfully synthesized within the tubular channels of anodic alumina membranes through an evaporation-induced selfassembly (EISA) process. Depending on the block copolymer structure directing agent employed, different mesophases could be observed. 2D-SAXS experiments and TEM measurements carried out on the calcined sample templated by Pluronic F127 showed that a 2D-hexagonal circular phase was predominantly formed within AAM channels, and that a hexagonal columnar structure was created as a minor phase. When using the template F108, which can form micelles with a higher curvature than Pluronic F127, a body centered cubic $(\operatorname{Im} \overline{3} \mathrm{~m})$ mesophase was achieved in the confined environment of the AAM channels.

It is noteworthy that the resulting circular and cubic 3a-OPVPMO/AAM composites were both structurally stable against thermal treatments at temperatures of up to $200{ }^{\circ} \mathrm{C}$ and also stable in the electron beam of the electron microscope, which is a remarkable enhancement over the previously reported flatsubstrate supported 3a-OPV-PMO films. Additionally, both the hierarchically synthesized nanostructured 3a-OPV-PMO/AAM composites were observed to be fluorescent in the visible light region. The fluorescence emission of the PMO/AAM composites showed a red-shift compared to that of the molecular precursor solution, indicating electronic interactions between the phenylenevinylene chromophores in the condensed organosilica networks. The success of achieving such stable, fluorescent and highly oriented mesoporous 3a-OPV-PMO materials suggests that these PMO/AAM composites and similar chromophorecontaining hierarchical nanostructures might offer potential for application in optoelectronic systems.

\section{Acknowledgements}

We thank the Deutsche Forschungsgemeinschaft through the SFB 486, the LMUexcellent program, the Nanosystems Initiative Munich (NIM cluster), and the China Scholarship Council (CSC) for supporting this work.

\section{References}

1 F. Hoffmann and M. Fröba, Chem. Soc. Rev., 2011, 40, 608620.

2 P. Van Der Voort, D. Esquivel, E. De Canck, F. Goethals, I. Van Driessche and F. J. Romero-Salguero, Chem. Soc. Rev., 2013, 42, 3913-3955.

3 T. Asefa, M. J. MacLachlan, N. Coombs and G. A. Ozin, Nature, 1999, 402, 867-871.

4 S. Inagaki, S. Guan, Y. Fukushima, T. Ohsuna and O. Terasaki, J. Am. Chem. Soc., 1999, 121, 9611-9614.

5 B. J. Melde, B. T. Holland, C. F. Blanford and A. Stein, Chem. Mater., 1999, 11, 3302-3308.

6 J. Morell, M. Gungerich, G. Wolter, J. Jiao, M. Hunger, P. J. Klar and M. Froba, J. Mater. Chem., 2006, 16, 2809-2818. 
7 A. Sayari and W. H. Wang, J. Am. Chem. Soc., 2005, 127, 12194-12195.

8 T. Tani, N. Mizoshita and S. Inagaki, J. Mater. Chem., 2009, 19, 4451-4456.

9 C. Vercaemst, P. E. de Jongh, J. D. Meeldijk, B. Goderis, F. Verpoort and P. Van Der Voort, Chem. Commun., 2009, 4052-4054.

10 A. Kuschel and S. Polarz, J. Am. Chem. Soc., 2010, 132, 65586565.

11 Q. H. Yang, J. Liu, L. Zhang and C. Li, J. Mater. Chem., 2009, 19, 1945-1955.

12 C. Li, J. Liu, X. Shi, J. Yang and Q. Yang, J. Phys. Chem. C, 2007, 111, 10948-10954.

13 M. Park, S. S. Park, M. Selvaraj, D. Y. Zhao and C. S. Ha, Microporous Mesoporous Mater., 2009, 124, 76-83.

14 R. Hernandez, A. C. Franville, P. Minoofar, B. Dunn and J. I. Zink, J. Am. Chem. Soc., 2001, 123, 1248-1249.

15 S. Inagaki, O. Ohtani, Y. Goto, K. Okamoto, M. Ikai, K. Yamanaka, T. Tani and T. Okada, Angew. Chem., Int. Ed., 2009, 48, 4042-4046.

16 P. N. Minoofar, R. Hernandez, S. Chia, B. Dunn, J. I. Zink and A. C. Franville, J. Am. Chem. Soc., 2002, 124, 14388-14396.

17 N. Mizoshita, Y. Goto, T. Tani and S. Inagaki, Adv. Funct. Mater., 2008, 18, 3699-3705.

18 W. Wang, J. E. Lofgreen and G. A. Ozin, Small, 2010, 6, 2621. 19 N. Mizoshita, M. Ikai, T. Tani and S. Inagaki, J. Am. Chem. Soc., 2009, 131, 14225-14227.

20 K. Kuraoka, Y. Tanaka, M. Yamashita and T. Yazawa, Chem. Commun., 2004, 1198-1199.

21 M. Trau, N. Yao, E. Kim, Y. Xia, G. M. Whitesides and I. A. Aksay, Nature, 1997, 390, 674-676.

22 A. Firouzi, D. J. Schaefer, S. H. Tolbert, G. D. Stucky and B. F. Chmelka, J.Am. Chem. Soc., 1997, 119, 9466-9477.

23 Y. Yamauchi, M. Sawada, T. Noma, H. Ito, S. Furumi, Y. Sakka and K. Kuroda, J. Mater. Chem., 2005, 15, 11371140.

24 H. Miyata, T. Noma, M. Watanabe and K. Kuroda, Chem. Mater., 2002, 14, 766-772.
25 H. Miyata, T. Suzuki, A. Fukuoka, T. Sawada, M. Watanabe, T. Noma, K. Takada, T. Mukaide and K. Kuroda, Nat. Mater., 2004, 3, 651-656.

26 R. L. Rice, D. C. Arnold, M. T. Shaw, D. Iacopina, A. J. Quinn, H. Amenitsch, J. D. Holmes and M. A. Morris, Adv. Funct. Mater., 2007, 17, 133-141.

27 B. Platschek, A. Keilbach and T. Bein, Adv. Mater., 2011, 23, 2395-2412.

28 A. Y. Ku, S. T. Taylor and S. M. Loureiro, J. Am. Chem. Soc., 2005, 127, 6934-6935.

29 K. Maeda, K. Ichinose, T. Yamazaki and T. Suzuki, Microporous Mesoporous Mater., 2008, 112, 603-611.

30 B. Platschek, N. Petkov and T. Bein, Angew. Chem., Int. Ed., 2006, 45, 1134-1138.

31 B. Platschek, N. Petkov, D. Himsl, S. Zimdars, Z. Li, R. Köhn and T. Bein, J. Am. Chem. Soc., 2008, 130, 1736217371.

32 Y. Y. Wu, G. S. Cheng, K. Katsov, S. W. Sides, J. F. Wang, J. Tang, G. H. Fredrickson, M. Moskovits and G. D. Stucky, Nat. Mater., 2004, 3, 816-822.

33 A. Yamaguchi, H. Kaneda, W. S. Fu and N. Teramae, Adv. Mater., 2008, 20, 1034-1037.

34 B. Yao, D. Fleming, M. A. Morris and S. E. Lawrence, Chem. Mater., 2004, 16, 4851-4855.

35 A. Keilbach, M. Döblinger, R. Köhn, H. Amenitsch and T. Bein, Chem.-Eur. J., 2009, 15, 6645-6650.

36 Y. Li, A. Keilbach, M. Kienle, Y. Goto, S. Inagaki, P. Knochel and T. Bein, J. Mater. Chem., 2011, 21, 1733817344.

37 C. J. Brinker, Y. F. Lu, A. Sellinger and H. Y. Fan, Adv. Mater., 1999, 11, 579-585.

38 B. Platschek, R. Köhn, M. Döblinger and T. Bein, ChemPhysChem, 2008, 9, 2059-2067.

39 J. Schuster, A. Keilbach, R. Köhn, M. Döblinger, T. Dörfler, T. Dennenwaldt and T. Bein, Chem.-Eur. J., 2011, 17, 94639470.

40 Y. Q. Wang, Y. J. Wang, C. M. Yang, G. Z. Lu and F. Schuth, Langmuir, 2006, 22, 5491-5496. 